\title{
The Analysis of Force Transfer between Feet during Backhand Short Serve in Elite Badminton Players
}

\author{
Vorramate Prajongjai $^{1}$, Saowanee Woravutrangkul ${ }^{2}$, Tatpicha Pongsiri ${ }^{3}$, Nongnapas Charoenpanich ${ }^{1, *}$ \\ ${ }^{1}$ Faculty of Sports Science, Chulalongkorn University, Bangkok, 10330, Thailand \\ ${ }^{2}$ Faculty of Physical Therapy, Huachiew Chalermprakiet University, Samutprakan, 10540, Thailand \\ ${ }^{3}$ Thailand National Sports University Trang Campus, Trang, 92140, Thailand
}

Received June 21, 2021; Revised August 10, 2021; Accepted August 27, 2021

\section{Cite This Paper in the following Citation Styles}

(a): [1] Vorramate Prajongjai, Saowanee Woravutrangkul, Tatpicha Pongsiri, Nongnapas Charoenpanich , "The Analysis of Force Transfer between Feet during Backhand Short Serve in Elite Badminton Players," International Journal of Human Movement and Sports Sciences, Vol. 9, No. 5, pp. 1011 - 1018, 2021. DOI: 10.13189/saj.2021.090523.

(b): Vorramate Prajongjai, Saowanee Woravutrangkul, Tatpicha Pongsiri, Nongnapas Charoenpanich (2021). The Analysis of Force Transfer between Feet during Backhand Short Serve in Elite Badminton Players. International Journal of Human Movement and Sports Sciences, 9(5), 1010 - 1018. DOI: 10.13189/saj.2021.090523.

Copyright@2021 by authors, all rights reserved. Authors agree that this article remains permanently open access under the terms of the Creative Commons Attribution License 4.0 International License

\begin{abstract}
The original badminton scoring system has been changed into the rally 21-point scoring system since 2006. The alteration allows badminton players to capably score a point in the first shot as service, causing them to equip themselves with faster-and-more precise style of play. Backhand short serve is most frequently used, especially in doubles, to improve the game situation as the players get an opportunity for attacking their opponents, and easily getting a score. The backhand short serve is executed by an upper part of the body which diagonally sends a shuttlecock over the net to land in a receiver's area within boundary line. Components of the service, however, are accompanied by not only the upper part of body but also the lower one. Therefore, the aim of this study was to study the accomplice of the lower part through analyzing the force transfer between feet at back swing, forward swing and contact during backhand short serve in elite badminton players. Fourteen Thai elite badminton double players (eight men and six female) were chosen to participate in the study. Two force plates which got set up in front of a badminton court behind short service line, and eight motion capture cameras installed around the court were used. The results revealed that there was a significant difference in anterior-posterior peak ground reaction force between left and right foot at back swing phase ( $\mathrm{p}=0.00)$, at forward swing phases $(\mathrm{p}=0.00)$ and at contact $(\mathrm{p}=0.00)$, and there was distinction in each phase of left foot between back swing with forward swing phase, back swing phase with contact, and forward swing phase with contact of
\end{abstract}

medial-lateral peak force $(p=0.008)$. Finally, right foot was found to show difference between back swing phase with contact, and forward swing phase with contact of vertical peak force $(\mathrm{p}=0.013)$. In conclusion, the ground reaction force was transferred from right foot to left foot for controlling the center of mass upon effective serving, and for preparing to hit the next shot.

Keyword Backhand Serve, Ground Reaction Force, Badminton Double, Elite Players

\section{Introduction}

Two hundred million people around the world are adherent to badminton games [1]. There are five disciplines in men's and women's singles, men's and women's doubles, and mixed doubles. In the past, badminton competitions stuck to a 15-point system whereby a player who won 2 of 3 sets would be a winner and could score a point only when they were in charge of a service. Since 2006, badminton's original scoring system have been changed into the 21-point scoring one in which a point can be scored at any turn [2]. Consequently, the competition style becomes more time-fit, speedy, and aggressive. The majority of players change their playing styles in a more precise manner so as to obtain a score by controlling the first turn - called a service whereby they 
possess the ability to utilize tactics in which they are not affected by opponents. The serve is very important in a game as being the star of a point, and being able to enhance the game. According to several studies, good serve lets an opponent work harder, which increases player's opportunity to obtain the score [3-7].

There are two serving styles: backhand and forehand serves both of which start from serving area and send a shuttlecock diagonally to opponent's receiving area within the boundary line. The starting and landing areas divide services into types: a short serve, a long serve, and a flick serve [8]. The good service allows an opponent to have difficulty in receiving and turning back the shuttlecock, thereby augmenting the opportunity to get a score $[3,5,6,8]$.

The most frequently-used serve, especially among players in the doubles, is a backhand short serve [6,9]. This service style is employed to delude an opponent by landing a shuttlecock on an uncertain area closest to short service line and midline, which culminates in the highest score in the French backhand short serves' test [10,11]. To perform the backhand short serve, the player stands on both feet in step-standing or parallel-standing posture. One hand pinches a shuttlecock while another hand grasps a racket and forces the shuttlecock to be sent over the net to land on an area behind short service line. Regarding the characteristics of backhand service, there are 4 phases: preparation phase, back swing phase, forward swing phase, and follow up phase (Figure 1.) $[3,8]$.

In the preparation phase, a player starts with placing a racket between the body and a shuttlecock. This posture let the player slightly lean forward in order to let the shuttlecock closest to the net, and to decrease the distance from opposite side [8,12]. After that, the player moves the racket back to the body and ends the phase before the racket changes the direction to the shuttlecock. The forward swing phase begins when the player pushes the racket forward until it reaches the shuttlecock (Contact). The badminton rules state that the shuttlecock should not be held higher than $115 \mathrm{~cm}$. when hit by the racket [13]. Then, the racket moves upward after contacting the shuttlecock, which is called the follow up phase. To control all 4 phases, the player should adjust the body to stabilize its lower limb and trunk for moving only upper part that is one of the most significant factors in landing the shuttlecock on effective target area $[14,15]$.

The backhand short serve requires fine movement control; player should balance their lower part of a body to be stabilized for improvement in the performance of service [15]. Both static and dynamic balance are important for the reduction on the risk of injury, and for augmentation in the level of performance $[15,16]$. Physiologically, the good stability not only enhances the performance of lower limb power, such as running speed, height of jumping, and swimming but also strengthens shoulder and arm muscles [17,18]. The postural control involves different underlying systems, the set of reflexes that triggers equilibrium response based on visual, vestibular, and somatosensory systems. The central nervous system (CNS) leads body movement to maintain equilibrium through controlling the body's center of mass (CoM) on both feet [16]. The lower part, both legs and trunk, is seemingly stabilized when a player takes the service. However, there are some controversies about the force transfer during service as to whether the transfer occurs upon leaning the body forward $[8,12]$ or staying constantly $[14,15]$. The movement of body CoM on both feet in terms of force transfer between feet and in each foot has, nonetheless, yet to be examined.

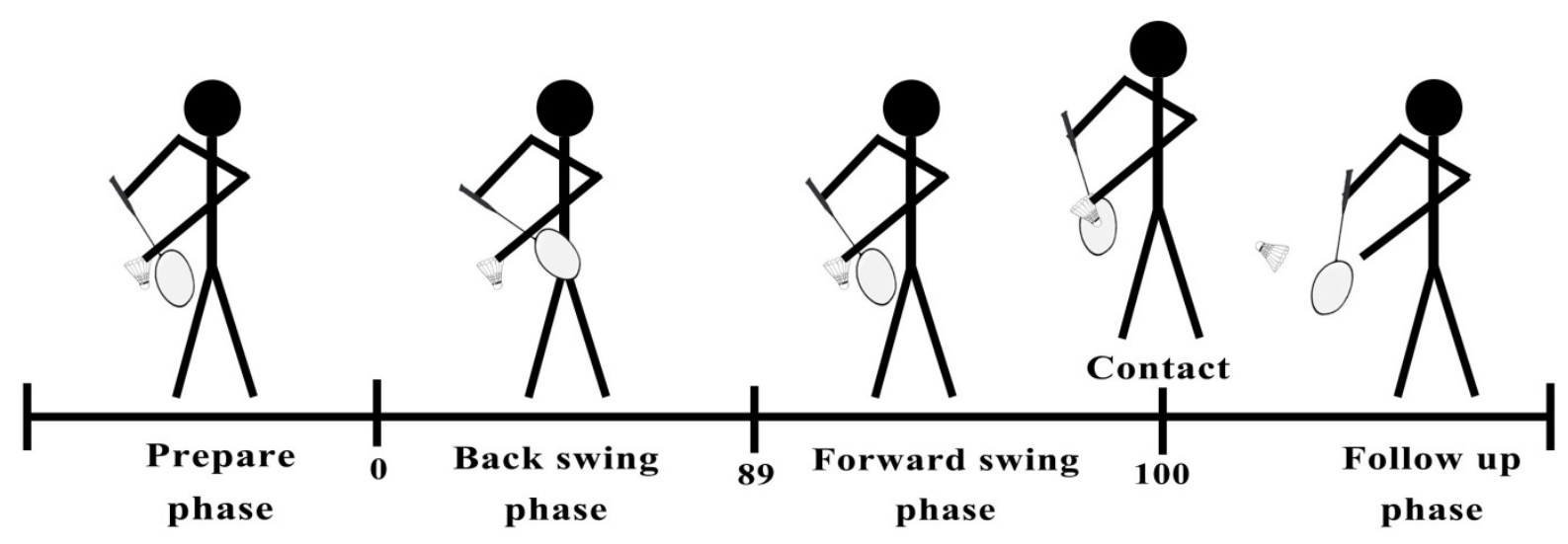

Figure 1. Four phases of Backhand short service; Prepare, back swing, Forward swing and follow up [3,8] 
Numerous biomechanics studies have investigated lower limb of badminton players, particularly in lunge. Chen, Wang, Wong, Lam and Zhang [19] looked into kinematic and kinetic of lower limb during forward forehand and backhand lunges in front of a badminton court. The result showed that peak compression contact force of ankle was enlarged, affecting to faster hip abduction, deceleration of CoM and torso during forehand lunge. Fu, Ren and Baker [20] found out knee and ankle ranges of motion of lunge for identifying the difference among badminton player's level. The result showed that amateur players illustrated larger ankle range of motion, joint inversion moment on the frontal plane, and joint internal rotation moment on the horizontal plane than elite ones. The elite players, in the meantime, illustrated larger knee joint moment in the sagittal and frontal planes than amateur ones. To prevent injury, badminton players should extend their knees with internal rotation, and train muscles around their ankles. Investigation by Huang, $\mathrm{Fu}$, Zhang, Fekete, Ren and Gu [21] unveiled right lunge, and hitting the shuttlecock with underarm stroke to the backcourt, and then coming back to starting position. Their results indicated that amateur players presented a greater range of movement, and of reverse joint moment at the frontal plane of ankle, and a greater joint internal rotation moment of the horizontal plane. Elite players, meanwhile, presented greater moment among the sagittal and frontal planes of knee joint. Most previous studies looked into lunge characteristic, discovering that the characteristic was over $15 \%$ in a badminton game as follows: half and forward lunges at 52.2 and 46.1 respectively [22]. To the best of our knowledge, lunge is open skill of badminton controlled by an opponent because a badminton player needs the best postural lunge prior to hitting the shuttlecock that flies back from the opponent. On the contrary, former studies overlooked ground reaction force of closed skill - one of badminton skills which could be controlled by players themselves in badminton as a service. At present, no studies have specifically investigated ground reaction force during serves.

Hence, the purpose of this study was to analyze the force transfer between both feet during backhand short serve in badminton athletes at back and forward swing phases, and contact. Our hypothesis was that the direction of force transfer between both feet would be transferred from back to front foot during back and forward swing phases, and contact of service. This information could assist coaches and sport scientists in prescribing training programs on organizing the body during performing a serve and preparing for the next shot.

\section{Materials and Methods}

\subsection{Participants}

Fourteen elite Thai badminton doubles athletes (six males and eight females) volunteered to partake in the study. Their mean age, height, and weight were $24.42 \pm 1.86$ years, $170.78 \pm 7.79 \mathrm{~cm}$, and $64.99 \pm 9.32 \mathrm{~kg}$, respectively. All athletes, all of whom were right hand dominant, were members of the badminton association of Thailand, and were at national level as attending Southeast Asian Games (SEA games), Asian games, and 300-1000 world tour tournaments. All athletes were healthy with no history of serious injuries for at least three months before data-collection date and received more than 60 points from the French backhand short serves' test $(r=0.95)[10,11]$. Prior to the study, each athlete was informed about purposes, procedures, and advantages of this study, and signed a written informed consent statement. Ethical approval was obtained by the Institute Ethics Review Committee for Research Involving Human Project, Thailand.

\subsection{Procedure}

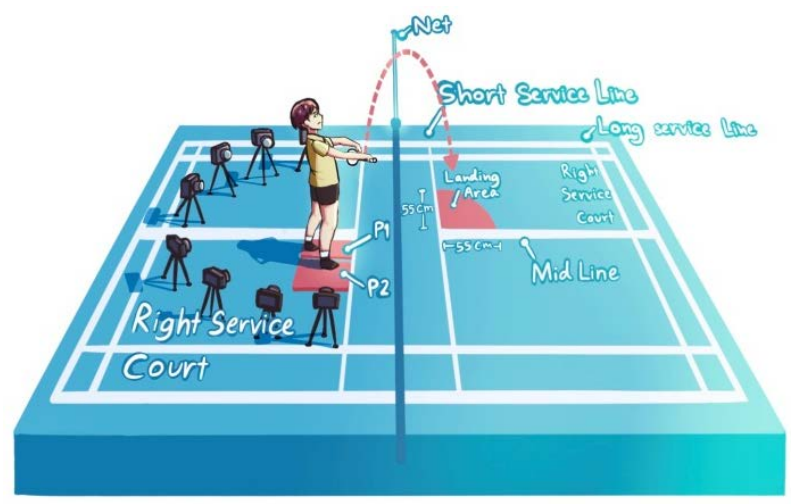

Figure 2. The Badminton court in laboratory

The badminton court was set in the biomechanical laboratory where the 2 force plates were installed at the front of the court. Eight cameras (Qualisys AB, Oqus7+, Sweden, $300 \mathrm{~Hz}$ ) were set around the court to show phases of movement $(r=0.97$, ICC $=0.88$ and 0.97$)[23,24]$ (Figure 2.), and the data at 10-12 am got collected every Wednesday. Each athlete was asked to place each foot on force plate I and II (Bertec, FP9090-15, USA, $1500 \mathrm{~Hz}$ ) (ICC $=0.75-0.9$, good to excellent) during trial [25]. Preparation posture of the athletes was step-standing one in which they placed a right foot slightly ahead of the left one. Athletes were asked to pinch a shuttlecock in a left hand positioned in front of the body, and to grasp a racket handle positioned between the body and the shuttlecock (Figure 2.). Then, each athlete was asked to perform a general warm-up for 10 minutes, and to be familiar with the backhand short serve. After the athletes were ready for performing the backhand short serve, data got collected until the shuttlecock landed on the target area. Twenty-one backhand short serves were performed, with three-minute rest between each serve. From both force plates, the 3-dimensional ground reaction force for only one serve which sent the shuttlecock to land on landing 
area closest to the short serve line and the midline was analyzed. The peak ground reaction force in three directions comprising anterior-posterior, medial-lateral and vertical force $(\mathrm{N})$ of three phases were collected.

\section{P1\&P2: Force plate I and II}

The phases of movement were detected through analyzing the movement of a racket and a shuttlecock. One retro-reflective markers were placed on racket's head and reflective tape got stuck to the shuttlecock's base (Figure 3.) $[1,26,27]$. The back swing phase started when a racket's head marker moved backward to the body until the phase stopped, and switched to the forward swing phase where this marker moved forward. The contact phase was that the frame before tape of shuttlecock began to move. One of the trials in which the shuttlecock got seen falling down the landing area nearest to short service and mid lines was selected for analysis.

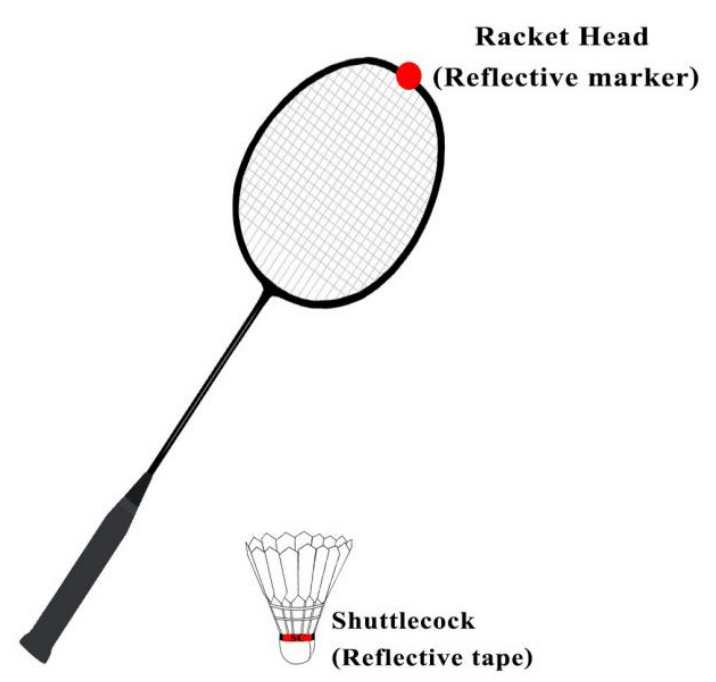

Figure 3. One retro-reflective marker on racket and one reflective tape on a shuttlecock

\subsection{Statistical Analyses}

All data were brought to calculating mean and standard deviation. The Kolmogorov Smirnov test was applied to analyze the data distribution. The dependent t-test (paired-samples t-test) was leveraged by the researcher to determine the difference of selected ground reaction forces between both feet. The t-test-based data was in normal distribution. On the other hand, the Wilcoxon signed rank test was employed with the data that was not in normal distribution. Meanwhile, the researcher utilized the one-way ANOVA to compare 3 phases of movement (back swing, forward swing, and contact phase) - in the form of normal distribution - with each other, and employed Friedman test for data on those phases which was not normally distributed. The standardized level of significance was set at 0.05 . All databases were analyzed in isolation through the identical statistical procedures with the use of IBM SPSS Statistics software (Version 21 for Mac; Armonk, NY, USA).

\section{Result}

The data of the trial in which the shuttlecock landed in the landing area closest to short service line and midline of all athletes were examined. The data distribution was presented in Table 1 whereas mean and standard deviation of left and right foot were illustrated in Table 2. The comparison between three phases was presented in Table 3.

Results of Table 1 unveiled that the peak vertical ground reaction force of right foot in all phases - back swing, forward swing and contact - were not in normal distribution $(\mathrm{p}<0.05)$. In the meantime, the peak ground reaction force of left foot, in all directions of force, was in normal distribution; moreover, the peak ground reaction force of right foot at anterior-posterior and medial-lateral direction were in normal distribution ( $\mathrm{p}>0.05$ ).

According to the Table 2, the peak ground reaction force in anterior-posterior and medial-lateral directions of the back swing and forward swing phases was compared through dependent t-test while as for the contact phase, the peak ground reaction force in anterior-posterior direction got compared as well through the identical tool. On the other hand, the peak ground reaction force in medial-lateral direction of the contact phase, and in vertical direction of all three phases were compared through the Wilcoxon Sign Rank test. The outcomes revealed significant difference between left and right feet in anterior-posterior direction belonging to the trio phases $(\mathrm{p}<0.05)$. 
Table 1. The test of normality (Kolmogorov-Smirnov, $n=14)$

\begin{tabular}{|c|c|c|c|}
\hline \multicolumn{2}{|c|}{ Component peak ground reaction force of backhand short serving } & \multirow[t]{2}{*}{ Statistic } & \multirow[t]{2}{*}{$p$} \\
\hline \multirow{8}{*}{$\begin{array}{l}\text { Back swing } \\
\text { phase }\end{array}$} & Left foot & & \\
\hline & - Anterior-posterior & .222 & .059 \\
\hline & - Medial-lateral & .190 & .181 \\
\hline & - Vertical & .189 & .189 \\
\hline & Right foot & & \\
\hline & - Anterior-posterior & .191 & .175 \\
\hline & - Medial-lateral & .212 & .089 \\
\hline & - Vertical & .281 & $.004 *$ \\
\hline \multirow{8}{*}{ Forward swing phase } & Left foot & & \\
\hline & - Anterior-posterior & .222 & .060 \\
\hline & - Medial-lateral & .225 & .053 \\
\hline & - Vertical & .211 & .091 \\
\hline & Right foot & & \\
\hline & - Anterior-posterior & .160 & .200 \\
\hline & - Medial-lateral & .180 & .200 \\
\hline & - Vertical & .273 & $.006^{*}$ \\
\hline \multirow{8}{*}{ Contact } & Left foot & & \\
\hline & - Anterior-posterior & .206 & .110 \\
\hline & - Medial-lateral & .253 & $.015^{*}$ \\
\hline & - Vertical & .211 & .091 \\
\hline & Right foot & & \\
\hline & - Anterior-posterior & .164 & .200 \\
\hline & - Medial-lateral & .158 & .200 \\
\hline & - Vertical & .263 & $.009 *$ \\
\hline
\end{tabular}

$* \mathrm{p}<0.05$

Table 2. Test result of Dependent t-test ( $\mathrm{t}$ ) and Wilcoxon Signed Rank test (z) between left and right feet of peak ground reaction force's component (n=14)

\begin{tabular}{|l|c|c|c|c|c|c|c|}
\hline \multirow{2}{*}{$\begin{array}{l}\text { Component peak ground reaction force of } \\
\text { backhand short serving }\end{array}$} & \multicolumn{2}{|c|}{ Left foot (N) } & \multicolumn{2}{|c|}{ Right foot (N) } & \multirow{2}{*}{$\mathbf{z}$} & \multirow{2}{*}{$\mathbf{p}$} \\
\cline { 2 - 8 } & Mean & SD & Mean & SD & & & \\
\hline $\begin{array}{l}\text { Back Swing Phase } \\
\text {-Anterior-posterior }\end{array}$ & -29.74 & 9.02 & 31.09 & 9.00 & -13.08 & & $.000^{*}$ \\
\hline -Medial-lateral & 2.36 & 13.25 & -3.72 & 15.62 & .796 & & .440 \\
\hline -Vertical & 327.73 & 127.36 & 332.49 & 131.04 & & -.031 & .975 \\
\hline $\begin{array}{l}\text { Forward Swing Phase } \\
\text {-Anterior-posterior }\end{array}$ & -29.99 & 8.86 & 30.78 & 8.22 & -14.046 & & $.000 *$ \\
\hline -Medial-lateral & 0.55 & 12.82 & -4.34 & 15.56 & .658 & & .522 \\
\hline -Vertical & 319.46 & 130.83 & 331.15 & 132.54 & & -.409 & .683 \\
\hline $\begin{array}{l}\text { Contact } \\
\text {-Anterior-posterior }\end{array}$ & -30.37 & 8.92 & 30.56 & 8.11 & -14.102 & & $.000 *$ \\
\hline -Medial-lateral & -0.16 & 13.42 & -5.13 & 15.82 & & -1.414 & .157 \\
\hline -Vertical & 313.91 & 134.56 & 328.19 & 130.82 & & -.408 & .683 \\
\hline
\end{tabular}

*p-value $<0.05$ 
Table 3. Test results of ANOVA (F) and Friedman test $\left(\lambda^{2}\right)$ among back swing, forward swing and during contact phase (n=14)

\begin{tabular}{|c|c|c|c|c|c|c|}
\hline \multirow{2}{*}{$\begin{array}{l}\text { Component peak ground reaction } \\
\text { force of backhand short serving }\end{array}$} & Back swing $(\mathrm{N})$ & Forward swing (N) & Contact (N) & \multirow{2}{*}{$\mathrm{F}$} & \multirow{2}{*}{$\lambda^{2}$} & \multirow{2}{*}{$\mathrm{p}$} \\
\hline & Mean \pm SD & Mean \pm SD & Mean \pm SD & & & \\
\hline $\begin{array}{l}\text { Left foot } \\
\text {-Anterior-posterior }\end{array}$ & $-29.74 \pm 9.02$ & $-29.99 \pm 8.86$ & $-30.37 \pm 8.92$ & .018 & & .982 \\
\hline -Medial-lateral & $2.36 \pm 13.25$ & $0.55 \pm 12.82$ & $-0.16 \pm 15.56$ & & 9.571 & $.008^{*, \#, \mathrm{~b}}$ \\
\hline -Vertical & $327.73 \pm 127.36$ & $319.46 \pm 130.83$ & $313.91 \pm 134.56$ & .039 & & .961 \\
\hline $\begin{array}{l}\text { Right foot } \\
\text {-Anterior-posterior }\end{array}$ & $31.09 \pm 9.00$ & $30.78 \pm 8.22$ & $30.56 \pm 8.11$ & .014 & & .986 \\
\hline -Medial-lateral & $-3.72 \pm 15.62$ & $-4.34 \pm 15.56$ & $-5.13 \pm 15.82$ & .029 & & .972 \\
\hline -Vertical & $332.49 \pm 131.04$ & $331.15 \pm 132.54$ & $328.19 \pm 130.82$ & & 8.764 & $.013^{\#, \mathrm{~b}}$ \\
\hline
\end{tabular}

F: from ANOVA test

$\lambda^{2}$ : from Friedman test

*: significant different between back swing phase and forward swing phase

\#: significant different between back swing phase and contact

$\beta$ : significant different between forward swing phase and contact

From Table 3, the researcher employed one-way ANOVA to compare mean and standard deviation among the back, forward and contact phases in anterior-posterior direction of both feet, medial-lateral direction of right foot and vertical direction of left foot, and used the Bonferroni test as a post hoc to ascertain which pairs were significantly different. Nevertheless, the Friedman test got leveraged to compare mean and standard deviation among the back, forward and contact phases belonging to medial-lateral direction of left foot, and to vertical direction of right foot; in addition, Wilcoxon Signed Rank test was utilized to find out which pairs of direction were significantly different. The results disclosed significant difference in medial-lateral direction of left foot as well as significant difference between back and forward swing phases, between back swing and contact phases, and between forward swing and contact phases. The outcomes also showed significant difference in peak vertical ground reaction force of right foot, and significant difference between back swing and contact phases, and between forward swing and contact phases

\section{Discussion}

To execute the backhand short serve, each athlete was asked to do step-standing posture, as the preparation phase, with a right foot placed in front of a left foot and a racket put between a shuttlecock and the body. The previous study suggested that the players should lean forward during serve to keep the shuttlecock falling closest to the net, and to decrease the distance from target area $[8,12]$. The later phases were back swing, forward swing, and follow up; consequently, the researcher ascertained which phases moved anteriorly to the net. The current hypothesis was then proved to find the force transfer from left to right foot due to the study-based starting posture of step-standing whereby a right foot was specified to be the front foot, and a left one was designated as the back foot. However, the present study revealed that probably, the peak ground reaction force of a right foot in anterior-posterior direction in all three phases: back swing, forward swing and contact was significantly higher than that of a left foot.

As a result, despite the preparation posture, athletes slightly leaned forward and would move their bodies near a net in exchange for shorter distance from the net, and for reduction in time for sending a shuttlecock to fall in the opponent's side. In the later phase, at back swing phase, the athletes began to transfer force from right to left foot until forward swing phase, and contact phase were reached respectively. This outcome differed from the previous study indicating that there was constant force between feet in stabilizing balance during a serve [14,15]. It may be explained that in this current study, all athletes were at elite level. The force transfer in this study, hence, showed that a well-trained athlete controlled the CoM while performing the backhand short serve. Whereas moving a racket backward and then forward, the athlete shifted the CoM backward to balance the upper part's movement that may be suggested to lead to good control over the shuttlecock's direction.

In addition, the results in Table 3 unveiled that the direction of peak ground reaction force in each foot brought about significant change in medial-lateral direction. The absolute peak ground reaction force of left foot increased owing to back swing, forward swing, and contact, respectively. The peak ground reaction force of right foot, meanwhile, decreased importantly in vertical ground reaction force. These current consequences supported the anterior-posterior direction of CoM during the backhand short serve performed. The body controlled the CoM through moving it from right to left foot, which was confirmed by the significant decline in vertical 
ground reaction force of right foot from the trio phases. Furthermore, the CoM in a left foot moved in medial-lateral direction throughout the three phases. These outcomes bolstered those of Masu, Muramatsu and Hayashi [15] indicating that whereas badminton players were hitting serves, good posture made them possess control over CoM - which was the base of support for manipulating the upper part's movement. Good balance of body's lower part could help the upper counterpart have fine movement, being capable of increasing effectiveness of service's consequence [14]. It may be said that a well-trained athlete control CoM through transferring the ground reaction force from front to back foot during a serve.

Additionally, this study selected the trial of the backhand short serve that sent the shuttlecock to fall in the landing area which was closest to short service line, and midline. It could be, thus, explained that the pattern of force transfer in this study was good at control over the CoM during the backhand short serve performed.

This force transfer pattern may be established by control of the CoM during a serve for the next rally. The former study indicated that it took $387 \mathrm{~ms}$ from service to receiving the next turn [9]. The body's position in a court influenced the playing performance, such as smash [28]. Therefore, athletes should possess backward control of the $\mathrm{CoM}$ in order to move their bodies to the center of the court in preparation for receiving the returned shuttlecock. It may be, accordingly, explained that the pattern of CoM transfer in this study was not only for counterbalancing the body's lower part but also for arranging to move the body in a good position for the next turn.

According to the current results, it may be indicated that to execute the excellent backhand short serve, athletes should be trained to controllably move the CoM backward, laterally from the front foot to the back one during the backhand short serve performed in preparation for the next turn. Because the badminton doubles discipline includes the rapid movement, the athletes are supposed to move at high speed in a powerful and accurate manner; hence, the high-speed specific strength exercise is interesting. Besides, Mahmoud Al-Haliq [29] suggested that not only speed-specific strength training program but also warm-up, skill performance, and final activity were important components for planning training programs. So as to improve the backhand short serve performance, specific training programs should, therefore, be considered.

\section{Conclusions}

The ground reaction force was transferred between two feet from front foot (Right foot) to back foot (Left foot). The ground reaction force in left foot was transferred in medial-lateral direction through the three phases of service. Additionally, the vertical ground reaction force of right foot lowered during those phases, which could be indicated that the direction of force in this pattern both promoted the upper part to perform effective backhand short serve and transferred the force in preparedness for the next turn. Accordingly, to boost the serving performance, players should be trained to move CoM backward while executing a serve for balancing and arranging for the next turn.

\section{REFERENCES}

[1] Kwan, M., Cheng, C.-L., Tang, W.-T., and Rasmussen, J., "Measurement of Badminton Racket Deflection during a Stroke". Sports Engineering, vol. 12 no. 3, pp. 143-153, 2010 DOI: 10.1007/s12283-010-0040-5.

[2] Phomsoupha, M. and Laffaye, G., "The Science of Badminton: Game Characteristics, Anthropometry, Physiology, Visual Fitness and Biomechanics". Sports Medicine, vol. 45 no. 4, pp. 473-495, 2015 DOI: 10.1007/s40279-014-0287-2.

[3] Shen, Y., "Kinematics Analysis on Fore-and Backhand Serve of Badminton". Applied Mechanics and Materials, vol. 540 no., pp. 317-320, 2014, https://doi.org/10.4028/w ww.scientific.net/AMM.540.317.

[4] Rusydi, M.I., Sasaki, M., Sucipto, M.H., and Windasari, N., "Study about Backhand Short Serve in Badminton Based on the Euler Angle" In 2015 4th International Conference on Instrumentation, Communications, Information Technology, and Biomedical Engineering (ICICI-BME), Bandung,Indonesia, (2-3 November, 2015), pp. 108-112. DOI: 10.1109/ICICI-BME.2015.7401345.

[5] Hussain, I., Ahmed, S., Mohammad, A., Khan, A., and Bari, M.A., "Videographical Analysis of Short Service in Badminton". Journal of Education and Practice, vol. 2 no. 2, pp. 1-5, 2011, http://citeseerx.ist.psu.edu/viewdoc/downloa d?doi=10.1.1.905.8923\&rep=rep1\&type=pdf.

[6] Gómez-Ruano, M.-Á., Cid, A., Rivas, F., and Ruiz, L.-M., "Serving Patterns of Women's Badminton Medalists in the Rio 2016 Olympic Games". Frontiers in Psychology, vol. 11 no., pp. 136, 2020 DOI: 10.3389/fpsyg.2020.00136.

[7] Ahmed, S., Bari, M.A., Ahmad, A., Mohammad, A., and Khan, A., "Analysis of Arm Movement in Badminton of ForehandLong and Short Service". Innovative Systems Design and Engineering, vol. 2 no. 3, pp. 13-17, 2011, https://iiste.org/Journals/index.php/ISDE/article/view/225/ 111.

[8] Woodward, M., "Badminton Coach Education Coaches' Manual Level 1" Kuala Lumpur, Malaysia. Badminton World Federation, 2011.

[9] Gawin, W., Beyer, C., Hasse, H., and Büsch, D., "How to Attack the Service: An Empirical Contribution to Rally Opening in World-Class Badminton Doubles". International Journal of Performance Analysis in Sport, vol. 13 no. 3, pp. 860-871, 2013, https://doi.org/10.1080/24748 668.2013.11868694. 
[10] Norkhalid Salimin., Julismah Jani., Mohd Izwan Shahril., and Elumalai, G., "Validity and Reliability of Comprehensive Assessment Instruments for Handball and Badminton Games in Physical Education". Asian Social Science, vol. 11 no. 23, pp. 12-21, 2015 DOI: 10.5539/ass. v11n23p12.

[11] French, E. and Stalter, E., "Study of Skill Tests in Badminton for College Women". Research Quarterly. American Association for Health, Physical Education and Recreation, vol. 20 no. 3, pp. 257-272, 1949 DOI: 10.1080/10671188.1949.10621035.

[12] Septian, W., Agus Wiyanto., Nurhadi, S., and Masri, "Backhand Serve Test Model for Junior Badminton Athletes". International Journal of Human Movement and Sports Sciences, vol. 9 no. 4A, pp. 112-118, 2021. DOI: 10.13189/saj.2021.091319.

[13] Badminton World Federation, "BWF Statutes, Laws of Badminton", Badminton World Federation, Kuala Lumpur, Malaysian. p. 1-14. 2021, https://extranet.bwfbadminton.c om/docs/document-system/81/1466/1470/Section\%204.1\% 20-\%20Laws\%20of\%20Badminton\%20-\%20Version\%20 1.0.pdf.https://extranet.bwfbadminton.com/docs/document -system/81/1466/1470/Section\%204.1\%20-\%20Laws\%20 of\%20Badminton\%20-\%20Version\%201.0.pdf.

[14] Wong, T.K., Ma, A.W., Liu, K.P., Chung, L.M., Bae, Y.-H., Fong, S.S., Ganesan, B., and Wang, H.-K., "Balance Control, Agility, Eye-Hand Coordination, and Sport Performance of Amateur Badminton Players: A Cross-Sectional Study". Medicine, vol. 98 no. 2, pp. 1-6, 2019 DOI: 10.1097/MD.0000000000014134.

[15] Masu, Y., Muramatsu, K., and Hayashi, N., "Characteristics of sway in the center of gravity of badminton players". Journal of physical therapy science, vol. 26 no. 11, pp. 1671-1674, 2014, https://doi.org/10.1589/jpts.26.1671.

[16] Horak, F.B., "Postural orientation and equilibrium: what do we need to know about neural control of balance to prevent falls?". Age and ageing, vol. 35 no. suppl_2, pp. ii7-ii11, 2006 DOI: 10.1093/ageing/afl077.

[17] Ika, N.M., Ari, s., and Vian, O., "The Effectiveness of Core Stability Exercises on Increasing Core Muscle Strength for Junior Swimming Athletes". International Journal of Human Movement and Sports Sciences, vol. 8 no. 6A, pp. 22-28, 2020 DOI: 10.13189/saj.2020.080704.

[18] Dinç, N. and Ergin, E., "The Effect of 8-Week Core Training on Balance, Agility and Explosive Force Performance". Universal Journal of Educational Research, vol. 7 no. 2, pp. 550-555, 2019. DOI:10.13189/ujer.2019.0 70227.

[19] Chen, T.L.-W., Wang, Y., Wong, D.W.-C., Lam, W.-K., and Zhang, M., "Joint contact force and movement deceleration among badminton forward lunges: a musculoskeletal modelling study". Sports Biomechanics, vol. AHEAD-OF-PRINT no., pp. 1-13, 2020, https://doi.org/10.1080/14763141.2020.1749720.

[20] Fu, L., Ren, F., and Baker, J.S., "Comparison of Joint
Loading in Badminton Lunging Between Professional and Amateur Badminton Players". Applied Bionics and Biomechanics, vol. 2017 no., pp. 8, 2017 DOI: 10.1155/2017/5397656.

[21] Huang, P., Fu, L., Zhang, Y., Fekete, G., Ren, F., and Gu, Y., "Biomechanical Analysis Methods to Assess Professional Badminton Players' Lunge Performance". Journal of Visualized Experiments: JoVE, vol. 148 no., pp. e58842, 2019 DOI: $10.3791 / 58842$

[22] Valldecabres, R., Casal, C.A., Chiminazzo, J.G.C., and De Benito, A.M., "Players' on-court movements and contextual variables in badminton world championship". Frontiers in Psychology, vol. 11 no. 1567, pp. 1-9, 2020 DOI: $10.3389 /$ fpsyg.2020.01567.

[23] Tomasevicz, C.L., Hasenkamp, R.M., Ridenour, D.T., and Bach, C.W., "Validity and reliability assessment of 3-D camera-based capture barbell velocity tracking device". Journal of science and medicine in sport, vol. 23 no. 1, pp. 7-14, 2020, https://doi.org/10.1016/j.jsams.2019.07.014.

[24] Gharib, N.M., Adel, S.M., and Kishk, N.A., "Reliability of three-dimensional motion analysis in assessment of Bell's palsy". Journal of American Science, vol. 7 no. 9, pp. 126-134, 2011, https://www.researchgate.net/profile/Sahar -Elhakk-2/publication/328334897_Reliability_of_three-di mensional_motion_analysis_in_assessment_of_Bell's_pals y/links/5bc7014b299bf17a1c5622ff/Reliability-of-three-di mensional-motion-analysis-in-assessment-of-Bells-palsy.p df.

[25] Walsh, M., Church, C., Hoffmeister, A., Smith, D., and Haworth, J., "Validation of a Portable Force Plate for Evaluating Postural Sway". Perceptual and Motor Skills, vol. 128 no. 1, pp. 191-199, 2021 DOI: 10.1177/0031512520945092.

[26] Tsai, C.-L., Hsueh, Y.-C., Pan, K.-M., and Chang, S.-S., "Biomechanical Analysis of Different Badminton Forehand Overhead Strokes of Taiwan Elite Female Players" In 26 International Conference on Biomechanics in Sports, Seoul, Korea, (July, 14-18, 2008), https://ojs.ub.uni-konstanz.de/c $\mathrm{pa} /$ article/view/1997.

[27] King, M., Towler, H., Dillon, R., and McErlain-Naylor, S., "A correlational analysis of shuttlecock speed kinematic determinants in the badminton jump smash". Applied Sciences, vol. 10 no. 4, pp. 1248, 2020, https://doi.org/10.3 390/app10041248.

[28] Li, S., Zhang, Z., Wan, B., Wilde, B., and Shan, G., "The Relevance of Body Positioning and Its Training Effect on Badminton Smash". Journal of Sports Sciences, vol. 35 no. 4, pp. 310-316, 2017, https://doi.org/10.1080/02640414.20 16.1164332 .

[29] Al-Haliq., M., "The Effect of a Training Program Using Speed-Specific Strength Exercises on Sensory-Motor Perception in Learning Stroke Forehand Smash in Badminton Material for Students of the Hashemite University". International Journal of Human Movement and Sports Sciences, vol. 8 no. 6, pp. 299-307, 2020 DOI: 10.13189/saj.2020.080601. 